\title{
The effect of insulin on response to intravitreal anti-VEGF injection in diabetic macular edema in type 2 diabetes mellitus
}

\author{
Rajya L. Gurung ${ }^{1 *} \mathbb{D}$, Liesel M. FitzGerald', Ebony Liu², Bennet J. McComish', Georgia Kaidonis², Bronwyn Ridge², \\ Alex W. Hewitt ${ }^{1,3}$, Brendan JT. Vote ${ }^{3}$, Nitin Verma ${ }^{3}$, Jamie E. Craig ${ }^{2}$ and Kathryn P. Burdon ${ }^{1}$
}

\begin{abstract}
Objectives: To assess whether insulin therapy impacts the effectiveness of anti-vascular endothelial growth factor (anti-VEGF) injection for the treatment of diabetic macular edema (DME) in type 2 diabetes mellitus.

Methods: This was a retrospective multi-center analysis. The best-corrected visual acuity (BCVA) at 12 months, BCVA change, central macular thickness (CMT), CMT change, and cumulative injection number were compared between the insulin and the oral hypoglycemic agent (OHA) groups.

Results: The mean final BCVA and CMT improved in both the insulin ( $N=137 ; p<0.001 ; p<0.001$, respectively) and the OHA group $(N=61 ; p=0.199 ; p<0.001$, respectively). The two treatment groups were comparable for final BCVA ( $p=0.263)$, BCVA change $(p=0.184)$, final CMT $(p=0.741)$, CMT change $(p=0.458)$, and the cumulative injections received $(p=0.594)$. The results were comparable between the two groups when stratified by baseline vision ( $p>0.05)$ and baseline HbA1c $(p>0.05)$.
\end{abstract}

Conclusion: Insulin therapy does not alter treatment outcomes for anti-VEGF therapy in DME.

Keywords: Diabetic macular edema, Anti-VEGF, Insulin, Visual acuity, Central macular thickness

\section{Introduction}

Diabetic macular edema (DME) is the most common cause of vision loss in both type 1 (T1) and type 2 (T2) diabetes mellitus (DM). The reported incidence of DME is highly variable ranging from 0 to $3 \%$ in newly diagnosed cases to $28-29 \%$ in chronic diabetic patients with over 20 years disease duration [1]. Similarly, the reported prevalence of DME ranges widely from $0.8-7.5 \%[2,3]$. The pathogenesis of DME is complex and poorly understood. Of the various risk factors, poor glycaemic control is well proven to increase the risk of DME $[4,5]$ and a large body of evidence supports the long-term beneficial

\footnotetext{
*Correspondence: rajyalaxmi.gurung@utas.edu.au

${ }^{1}$ Menzies Institute for Medical Research, University of Tasmania, 17 Liverpool Street (Private Bag 23), Hobart, Tas 7000, Australia

Full list of author information is available at the end of the article
}

effects of tight glycemic control in diabetic patients [6]. Consequently, insulin is one of the most widely used hypoglycemic agents in all forms of DM [7, 8], with the benefit of improving glycemic control in addition to lowering rates of diabetes-related complications. However, insulin use can have unintended effects, with reports of increased cardiovascular events and increased colorectal cancer in patients on insulin therapy $[9,10]$. There are also several reports of increased risk of DME with the use of insulin therapy in diabetics [11]. Intensive insulin therapy was first linked to retinopathy in the 1980 s in T1 diabetes patients [12]. Since then, there have been similar reports of worsening of diabetic retinopathy (DR), including DME, in T2 diabetic patients taking insulin therapy for glycemic control $[13,14]$. A study by Zapata et al. showed an increased risk of diffuse DME in T2 original author(s) and the source, provide a link to the Creative Commons licence, and indicate if changes were made. The images or other third party material in this article are included in the article's Creative Commons licence, unless indicated otherwise in a credit line to the material. If material is not included in the article's Creative Commons licence and your intended use is not permitted by statutory regulation or exceeds the permitted use, you will need to obtain permission directly from the copyright holder. To view a copy of this licence, visit http://creativecommons.org/licenses/by/4.0/. The Creative Commons Public Domain Dedication waiver (http://creativeco mmons.org/publicdomain/zero/1.0/) applies to the data made available in this article, unless otherwise stated in a credit line to the data. 
diabetics on insulin therapy (odds ratio $=1.4, p=0.036$ ) [15]. Additionally, a meta-analysis of 14 studies showed insulin treatment to be associated with increased risk of DME (relative risk $=3.416 ; 95 \% \mathrm{CI}=2.42,4.83$ ) [11]. The higher risk of DR progression amongst the insulin group may partly be attributed to disease severity, and DR continues to progress despite intensive insulin therapy [16, 17]. In these patients, the association with insulin treatment might simply reflect the severity of the underlying disease rather than the adverse effect of insulin treatment. Nevertheless, other studies have demonstrated insulin therapy to be an independent risk factor for DR and DME $[15,18]$. Further, a meta-analysis by Zhao et al. clearly showed that the association of insulin with DME risk is independent of baseline glycosylated hemoglobin (HbA1c) levels [19].

Various hypotheses have been proposed to explain the adverse effect of insulin therapy, though the exact underlying molecular mechanisms remain elusive. Insulin acts as a growth factor and it is hypothesized to worsen DR severity by promoting 1 ) endothelial cell proliferation [20], 2) loss of basement membrane and surrounding pericytes [21], and 3) synthesis of pro-angiogenic factors like VEGF [22]. Insulin increases the expression of VEGF receptors and reactive oxygen species, which in turn triggers retinal neovascularization and DME. In support of this hypothesis, rapid glycemic control in diabetic rat models has shown increased expression of VEGF mRNA and protein levels mediated by hypoxia-inducible factor-1 $\alpha$ [23]. Similarly, another study found increased vascular leakage in mice treated with insulin, apparently involving betacellulin mediated epidermal growth factor signaling pathway [24]. A study of T2 diabetic patients by Henricsson et al. [13] found elevated levels of IGF1 , a protein that can decrease blood glucose levels, in patients who had worsening of DR three years after insulin initiation.

Thus, the association of insulin with increased risk and severity of DME may have an impact on response to intraocular anti-VEGF therapy, the latest standard of care for DME. To date, there are very few studies investigating the possible influence of insulin therapy on response to anti-VEGF injection $[25,26]$. The aim of the present study was, therefore, to assess whether insulin therapy in T2DM patients impacts DME response to anti-VEGF therapy compared with using oral hypoglycemic agents (OHA).

\section{Methodology}

\section{Study design}

This was a retrospective multi-center study. Participants were selected from one of two studies, the Tasmanian Ophthalmic Biobank (University of Tasmania) or the
Genetic Risk Factors in Complications of Diabetes (Flinders University). The Tasmanian Ophthalmic Biobank is a collaboration between the University of Tasmania and Tasmanian eye clinics established to collect clinical information and DNA samples from residents of Tasmania with a variety of ocular diagnoses. For enrolment, participants must have had a recent ophthalmic examination and be over 18 years of age. The Genetic Risk Factors in Complications of Diabetes is based at Flinders University (Adelaide, Australia) and includes patients over the age of 18 years with a diagnosis of $\mathrm{T} 1$ diabetes or medically treated $\mathrm{T} 2$ diabetes.

\section{Participants}

Patients, who commenced any intravitreal anti-VEGF injections (Aflibercept, Regeneron; Bevacizumab, Genentech; Ranibizumab, Novartis;) between 2013 and 2019 for the treatment of DME secondary to T2 diabetes were identified from both cohorts for inclusion in this study. DME cases were defined as those with clinically diagnosed center-involving DME and confirmed by central macular thickness $(\mathrm{CMT}) \geq 315$ microns as measured by spectral-domain optical coherence tomography (SDOCT; Heidelberg Spectralis; Heidelberg Engineering Inc., Heidelberg, Germany). Eyes with cysts in the central 1000 microns were also included in this study, independent of the CMT parameter. This study excluded patients who had undergone vitreoretinal surgery or had received any systemic anti-VEGF therapy or intra-ocular steroid in the six months preceding the initiation of anti-VEGF injection. Further, DME patients with severe media opacity obstructing clear visualization of the macula, and/or with incomplete follow-up data were also excluded from the study. All treatment decisions, including the type of anti-VEGF injection, the treatment, and the re-treatment criteria were based at the discretion of the treating physician. The better responding eye was included as the study eye for patients receiving bilateral anti-VEGF injections.

\section{Clinical data collection}

Data for 12 months after the date of the first injection was collected retrospectively from the electronic database. The data included clinical and demographic characteristics: age, sex, lipid profile, hypertensive status, diabetic nephropathy status, duration of diabetes, baseline glycemic control (HbA1c), smoking status, best-corrected visual acuity (BCVA), CMT, intraocular pressure (IOP), laterality of the injected eye, lens status, duration of retinopathy, severity of retinopathy, panretinal photocoagulation (PRP) at baseline, anti-VEGF injections (number and type) and adverse drug events during/post-injection. Both proliferative diabetic retinopathy and severe non-proliferative diabetic retinopathy 
were combined as the severe DR group. Hypertension was defined as systolic BP level of $\geq 140 \mathrm{mmHg}$ and/ or diastolic BP level of $\geq 90 \mathrm{mmHg}$ or any participants on antihypertensive medications. Likewise, hyperlipidemia was defined as total cholesterol greater than or equal to $4 \mathrm{mmol} / \mathrm{L}$, or current use of lipid-lowering medication. Nephropathy was defined as the presence of microalbuminuria (30-300 mg/d) or macroalbuminuria $(>300 \mathrm{mg} / \mathrm{d})$ or patients undergoing dialysis or who had received renal transplantation. Diabetes treatment categories were defined as OHA group vs insulin group. The insulin group comprised of participants taking only insulin or insulin in combination with other OHAs and, the OHA group comprised of participants taking only oral medication(s) for diabetic control. The date/year of insulin therapy initiation, formulation of insulin therapy, and the types of OHA were also noted if data were available. For statistical analysis, Snellen's best-corrected visual acuity (BCVA) was converted to approximate early treatment diabetic retinopathy study (approxETDRS) letter scores [27].

\section{Outcome measures}

The primary outcome was final BCVA at 12 months after the first intravitreal anti-VEGF injection. Secondary outcomes included final CMT and cumulative number of injections over 12 months. These outcomes were compared between the insulin and OHA treatment groups. The BCVA change and CMT change at the end of 12 months were also compared between the two groups.

To explore the effects of likely confounding factors, we also stratified the participants based on baseline vision ( $<70$ approxETDRS vs $\geq 70$ approxETDRS) and HbA1c level $(\leq 7.0 \mathrm{~g} / \mathrm{dl}$ vs $>7.0 \mathrm{~g} / \mathrm{dl})$. We then explored difference in outcomes when limiting the cohort to those with good final vision (vs $\geq 70$ approxETDRS) to ensure the effects were not due to greater variability in visual acuity measures in patients with poor vision.

\section{Statistical analysis}

Statistical analyses were performed using $\mathrm{R}$ version 4.0.2 (http://www.R-project.org/). Descriptive statistics included the mean with standard deviation (SD) and median (minimum-maximum) for numerical variables. After assessing the normality of all quantitative variables by visualizing the $\mathrm{Q}-\mathrm{Q}$ plot and histogram outputs, parametric or non-parametric tests were applied where applicable. Paired $t$-test was used to compare final vision and final CMT with baseline values in each treatment group (insulin and OHA group). Between-group analyses of the two treatment groups were undertaken using the independent $\mathrm{t}$-test or the Mann-Whitney $\mathrm{U}$ test for continuous variables and the Chi-square test for categorical variables. Sex (male:female), hyperlipidemia (yes:no), hypertension (yes:no), nephropathy (yes:no), smoking status (yes:no), severe DR (yes:no), PRP at baseline (yes:no), laterality of eye $(R / L)$ and lens status (phakic:pseudophakic) were dichotomized for statistical analyses. A multivariable linear regression analysis was conducted to account for any confounding effect of the baseline characteristics. Clinically relevant variables from previous studies and those significant in the univariable analyses were selected for the multivariable regression. Tests were considered significant at $p<0.05$.

\section{Results}

A total of 255 diabetic patients receiving anti-VEGF injections were identified. Of these, 35 were T1DM patients and were excluded from the study. Of the remaining $220 \mathrm{~T} 2$ patients, 198 met the inclusion criteria. The baseline and clinical characteristics stratified by treatment (insulin vs OHA) are summarized in Table 1. There were 137 patients in the insulin group and 61 in the OHA group. The two groups were comparable in their baseline BCVA, baseline CMT, age, sex, duration of DR, BMI, laterality of eye, hyperlipidemic and smoker status, and the type of anti-VEGF injections received. However, the insulin group had a significantly longer duration of DM $(p<0.001)$, more severe grade of DR $(p=0.028)$, poorer DM control $(p=0.033)$, a higher proportion of hypertensive patients $(p=0.014)$, and a greater proportion of nephropathy $(p=0.002)$ compared to the OHA group. Likewise, more patients in the insulin group had received PRP laser therapy $(p=0.002)$, whereas more patients had undergone cataract surgery $(p=0.019)$ in the OHA group. Bevacizumab was the chosen anti-VEGF agent in more than half the patients in each treatment group (insulin $=54.70 \%$; OHA $=55.70 \%$ ).

\section{Outcome measures according to diabetes treatment type}

After 12 months of anti-VEGF treatment, the mean final BCVA (68.33 \pm 12.68 approxETDRS letters) improved significantly from baseline $(64.08 \pm 12.99$ approxETDRS letters) in the insulin group $(p<0.001,95 \% \mathrm{CI}=2.34$, $6.14)$. In the OHA group, the final BCVA $(65.98 \pm 15.44$ approxETDRS letters) increased from baseline (64.07 \pm 12.60 approxETDRS letters), although the improvement was not statistically significant $(\mathrm{p}=0.199$, $95 \% \mathrm{CI}=-1.04,4.87$ ). The two groups had similar final $\mathrm{BCVA}$ at the end of 12 months $(p=0.263,95 \% \mathrm{CI}=-1.77$, 6.46), (Fig. 1).

Furthermore, the final CMT (insulin $=318.90 \pm 68.86$ microns; $\mathrm{OHA}=322.74 \pm 88.55$ microns) was significantly reduced from baseline (insulin $=380.33 \pm 101.54$ microns; OHA $=396.64 \pm 113.77$ microns) in both treatment groups, (insulin $=p<0.001,95 \% \mathrm{CI}=-78.68,-44.17$; 
Table 1 Baseline and clinical characteristics of patients in each treatment group

\begin{tabular}{|c|c|c|c|}
\hline Variables & Insulin $(N=137)$ & $\mathrm{OHA}(N=61)$ & $P$ value \\
\hline Baseline BCVA (approxETDRS letters) & $64.08(12.99)$ & $64.07(12.60)$ & 0.994 \\
\hline Baseline CMT (microns) & $380.33(101.54)$ & $396.64(113.77)$ & 0.316 \\
\hline Lens status (\% Pseudophakic) & 62.80 & 78.70 & 0.019 \\
\hline Age (years) & $68.19(10.12)$ & $69.43(10.34)$ & 0.431 \\
\hline Male (\%) & 64 & 31 & 0.497 \\
\hline Laterality of eye (\% RE) & 46.70 & 50.80 & 0.352 \\
\hline Hypertension (\% positive) & 89.10 & 75.40 & 0.014 \\
\hline Hyperlipidemia (\% positive) & 89.80 & 86.90 & 0.354 \\
\hline Nephropathy (\% positive) & 64.20 & 41.00 & 0.002 \\
\hline Smoker (\%) & 48.90 & 52.50 & 0.379 \\
\hline BMI (\%) & $34.38(7.50)$ & $32.47(8.08)$ & 0.108 \\
\hline Diabetes duration (years) & $22.41(8.17)$ & $17.95(9.55)$ & $<0.001$ \\
\hline $\mathrm{HbA} 1 \mathrm{c}(\mathrm{mg} / \mathrm{dl})$ & $8.66(1.71)$ & $7.68(1.21)$ & 0.033 \\
\hline PRP at baseline (\% positive) & 47.40 & 24.60 & 0.002 \\
\hline DR duration (years) & $7.74(4.06)$ & $7.62(3.42)$ & 0.848 \\
\hline Severe DR (\%) & 51.80 & 36.10 & 0.028 \\
\hline Injection type & & & 0.599 \\
\hline Bevacizumab (\%) & 54.70 & 55.70 & \\
\hline Ranibizumab (\%) & 17.50 & 23.00 & \\
\hline Aflibercept (\%) & 11.70 & 11.50 & \\
\hline Mixed (\%) & 16.10 & 9.80 & \\
\hline
\end{tabular}

Abbreviations: BCVA Best corrected visual acuity, BMI Body-mass index, CMT Central macular thickness, DR Diabetic retinopathy, approxETDRS Approximate early treatment diabetic retinopathy study, $O H A$ Oral hypoglycemic agent, $P R P$ Pan-retinal photocoagulation, $R E$ Right-eye. Data are presented as means (SD) for continuous variables and percentage (\%) for categorical variables. Independent t-test was conducted for continuous variables and Chi-square test for categorical variables. Significant $p$-values are in bold

$\mathrm{OHA}=p<0.001, \quad 95 \% \mathrm{CI}=-105.37,-42.42)$. However, there was no significant difference in final CMT between the treatment groups, $(p=0.741,95 \% \mathrm{CI}=-26.74,19.06)$, (Fig. 1). Likewise, the two treatment groups received similar number of injections by the end of 12 months, (insulin $=8.25 \pm 3.04 ; \quad \mathrm{OHA}=8 \pm 3.26 ; \quad p=0.594$, $95 \% \mathrm{CI}=-0.69,1.20$ ). The change in vision (insulin $=4.25 \pm 11.24$; $\mathrm{OHA}=1.92 \pm 11.55)$ and CMT (insulin $=-61.42 \pm 102.13 ; \quad \mathrm{OHA}=-73.90 \pm 122.89)$ was also comparable between the two groups (BCVA change, $p=0.184,95 \% \mathrm{CI}=-1.11,5.77$; CMT change, $p=0.458$, $95 \% \mathrm{CI}=-20.58,45.53)$.

\section{Outcome measures stratified by baseline vision and DM control}

For patients with mean baseline $\mathrm{BCVA}<70$ approxETDRS letters, there was no significant difference in the final BCVA, BCVA change, CMT outcomes, or cumulative injection number across the two treatment groups, $(p>0.05)$, Table 2. Likewise, the final BCVA, BCVA change, final CMT, CMT change, and number of injections were also comparable across the two groups for the cohort with BCVA $\geq 70$ approxETDRS letters $(p>0.05)$, Table 2. Similarly, no significant difference was observed between the two groups when stratified according to DM control $(\mathrm{HbA} 1 \mathrm{c}>7.0$ or $\leq 7.0 \mathrm{~g} / \mathrm{dl})$, with both groups having comparable outcomes across all the parameters $(p>0.05)$, Table 3 .

As several measures were significantly different between the two treatment groups at baseline (Table 1), a multivariable regression analysis was done to look at the possible confounding effect of these baseline parameters on the final BCVA (Additional File: Supplementary S1). However, even after adjusting for all the potential confounders, the final BCVA was found to be comparable between the insulin and OHA groups.

When stratified by injection type (bevacizumab and ranibizumab), the insulin and OHA groups showed comparable final visual and CMT outcomes after 12 months, (Additional File: Supplementary S2). A separate analysis for "aflibercept" and "mixed injection" was not done owing to the small cohort sizes (Table 1).

A further sub-analysis including only patients with good outcome at the end of 12 months i.e. final BCVA $\geq 70 \quad$ approxETDRS $\quad(N=120 ; \quad$ Insulin $=86$, $\mathrm{OHA}=34$ ) also did not show any significant difference in the visual and CMT outcome between the two treatment groups, (Additional File: Supplementary S3). 

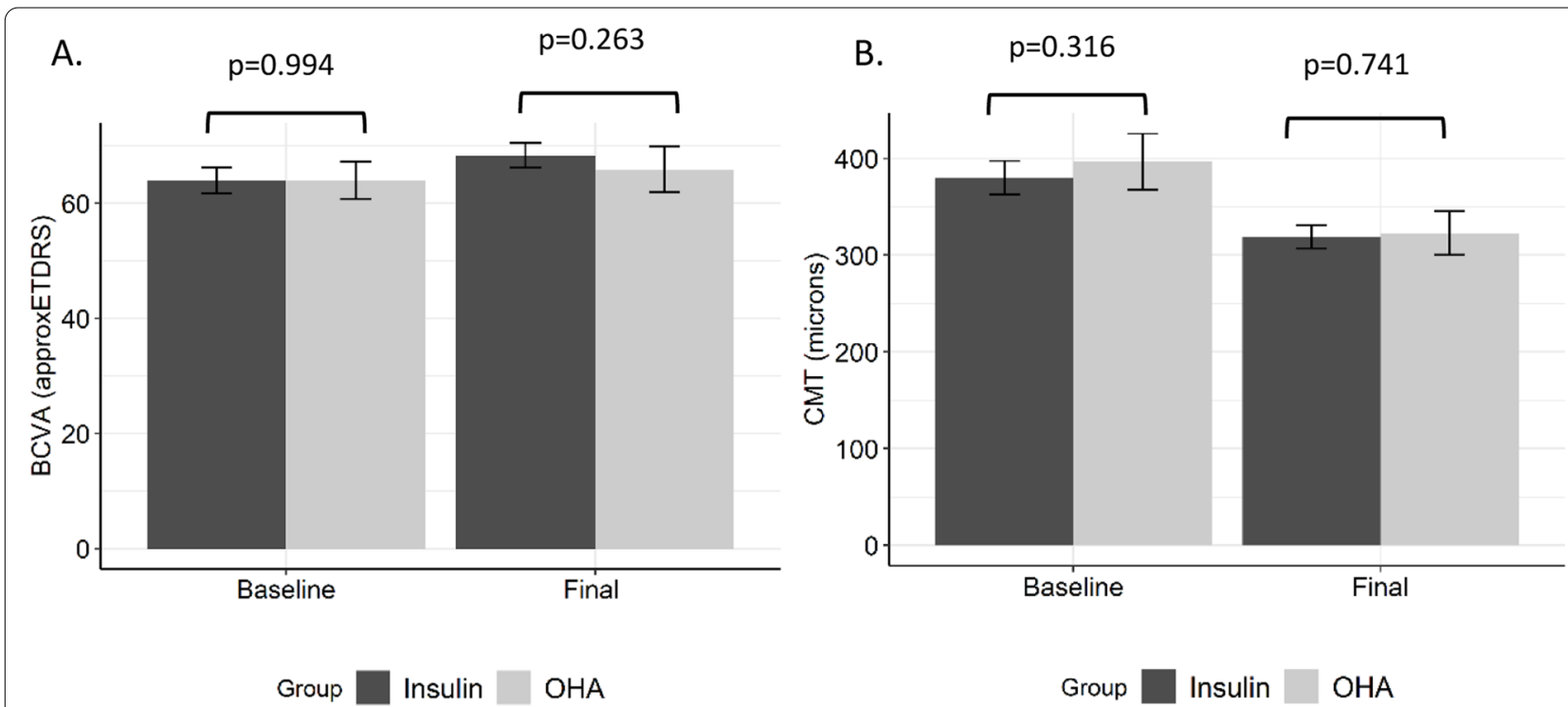

Fig. 1 Best-corrected visual acuity and central macular thickness outcome at baseline and the end of 12 months (final) of anti-VEGF therapy by type of diabetes treatment. BCVA: best-corrected visual acuity; approxETDRS: approximate early treatment diabetic retinopathy study; CMT: central macular thickness; OHA: oral hypoglycemic agent; error bars represent 95\% confidence interval for mean; $p$ value is for comparing the BCVA and CMT between the treatment groups at each visit

\section{Discussion}

In our study, patients in both the insulin and OHA groups had comparable visual and anatomical outcomes in response to anti-VEGF therapy for the treatment of DME. There was no significant difference between the groups in terms of final BCVA, final CMT, BCVA/CMT change, and cumulative injection number. However, the insulin group had worse DM control at presentation, reflected by a significantly higher baseline HbA1c compared to the OHA group. We therefore conducted a sub-analysis stratified by baseline HbA1c to test for any influence of baseline DM control on the outcome,

Table 2 Anti-VEGF treatment outcome in patients receiving insulin or OHA for DM, stratified by baseline vision

\begin{tabular}{|c|c|c|c|}
\hline & Insulin & OHA & $P$ value ${ }^{*}(95 \% \mathrm{Cl})$ \\
\hline BCVA $\geq 70$ approxETDRS letters & $N=75$ & $N=32$ & \\
\hline Baseline BCVA (approxETDRS letters) & $73.53(3.61)$ & $73.03(4.02)$ & $0.546(-1.15,2.15)$ \\
\hline Final BCVA (approxETDRS letters) & $73.88(5.81)$ & $73.66(6.51)$ & $0.867(-2.45,2.89)$ \\
\hline BCVA change (approxETDRS letters) & $0.35(6.08)$ & $0.62(6.99)$ & $0.689(-4.99,1.00)$ \\
\hline Baseline CMT (microns) & $345.84(58.56)$ & $356.19(81.10)$ & $0.517(-42.27,21.57)$ \\
\hline Final CMT (microns) & $302.73(47.29)$ & $316.16(69.98)$ & $0.326(-40.68,13.83)$ \\
\hline CMT change (microns) & $-43.09(63.88)$ & $-40.03(86.81)$ & $0.624(-32.00,21.00)$ \\
\hline Injection number & $8.21(2.99)$ & $8.03(3.08)$ & $0.779(-1.11,1.47)$ \\
\hline BCVA $<70$ approxETDRS letters & $N=62$ & $N=29$ & \\
\hline Baseline BCVA (approxETDRS letters) & $52.65(10.86)$ & $54.17(11.36)$ & $0.547(-6.58,3.53)$ \\
\hline Final BCVA (approxETDRS letters) & $61.61(15.28)$ & $57.52(17.96)$ & $0.294(-3.66,11.85)$ \\
\hline BCVA change (approxETDRS letters) & $8.97(13.99)$ & $3.34(15.10)$ & $0.063(0.00,10.00)$ \\
\hline Baseline CMT (microns) & 422.05 (124.99) & $441.28(128.52)$ & $0.505(-76.69,38.24)$ \\
\hline Final CMT (microns) & $338.45(84.56)$ & $330(106.18)$ & $0.708(-36.26,91.62)$ \\
\hline CMT change (microns) & $-83.60(131.88)$ & $-111.28(145.80)$ & $0.259(-26.00,81.99)$ \\
\hline Injection number & $8.31(3.13)$ & $7.97(3.51)$ & $0.657(-1.19,1.87)$ \\
\hline
\end{tabular}

Abbreviations: BCVA Best corrected visual acuity, CMT Central macular thickness, CI Confidence interval, DM Diabetes mellitus, approxETDRS Approximate early treatment diabetic retinopathy study, $\mathrm{OHA}$ Oral hypoglycemic agent

Data are presented as means (SD) for continuous variables and percentage (\%) for categorical variables. $\mathrm{N}$ represents the total case number in each group. ${ }^{*} p$-values are for a difference between insulin and OHA group. $95 \% \mathrm{Cl}$ is for the difference between the means of the two groups. Independent t-test/ Mann-Whitney $\mathrm{U}$ test for continuous variables between treatment groups; Significant $p$-values are in bold 
Table 3 Outcome stratified by baseline $\mathrm{HbA} 1 \mathrm{c}$ level

\begin{tabular}{|c|c|c|c|}
\hline & Insulin & OHA & $P$ value $*(95 \% \mathrm{Cl})$ \\
\hline $\mathrm{HbA} 1 \mathrm{c}>7.0 \mathrm{~g} / \mathrm{dl}$ & $N=111$ & $N=40$ & \\
\hline Baseline BCVA (approxETDRS letters) & $64.88(12.14)$ & $63.05(14.42)$ & $0.476(-3.27,6.94)$ \\
\hline Final BCVA (approxETDRS letters) & $69.76(9.51)$ & $65.68(16.48)$ & $0.145(-1.46,9.62)$ \\
\hline BCVA change (approxETDRS letters) & $4.87(10.11)$ & $2.63(12.75)$ & $0.434(-1.00,5.00)$ \\
\hline Baseline CMT (microns) & $386.16(109.14)$ & $393.25(119.46)$ & $0.743(-50.12,35.95)$ \\
\hline Final CMT (microns) & $319.37(69.67)$ & $315.05(84.72)$ & $0.774(-25.57,34.21)$ \\
\hline CMT change (microns) & $-66.78(107.51)$ & $-78.20(123.30)$ & $0.704(-24.00,34.99)$ \\
\hline Injection number & $8.27(3.08)$ & $7.60(3.22)$ & $0.259(-0.50,1.84)$ \\
\hline $\mathrm{HbA} 1 \mathrm{c} \leq 7.0 \mathrm{~g} / \mathrm{dl}$ & $N=26$ & $N=21$ & \\
\hline Baseline BCVA (approxETDRS letters) & $60.65(15.95)$ & $66.00(8.06)$ & $0.145(-12.61,1.91)$ \\
\hline Final BCVA (approxETDRS letters) & $62.23(20.70)$ & $66.57(13.60)$ & $0.393(-14.48,5.80)$ \\
\hline BCVA change (approxETDRS letters) & $1.58(15.14)$ & $0.57(8.97)$ & $0.845(-5.00,5.00)$ \\
\hline Baseline CMT (microns) & $355.42(53.72)$ & $403.10(104.55)$ & $0.068(-99.11,3.77)$ \\
\hline Final CMT (microns) & $316.88(66.58)$ & $337.38(95.82)$ & $0.411(-70.57,29.58)$ \\
\hline CMT change (microns) & $-38.54(72.18)$ & $-65.71(124.70)$ & $0.391(-26.99,89.99)$ \\
\hline Injection number & $8.19(2.91)$ & $8.76(3.28)$ & $0.538(-2.42,1.28)$ \\
\hline
\end{tabular}

Abbreviations: BCVA Best corrected visual acuity, CMT Central macular thickness, CI Confidence interval, approxETDRS Approximate early treatment diabetic retinopathy study, OHA Oral hypoglycemic agent

Data are presented as means \pm SD. $\mathrm{N}$ represents the total case number (percentage) in each group. * $p$-values are for a difference between insulin and $\mathrm{OHA}$ group. $95 \% \mathrm{Cl}$ is for the difference between the means of the two groups. Independent $\mathrm{t}$-test/Mann-Whitney $\mathrm{U}$ test for continuous variables between treatment groups; Significant $p$-values are in bold

however, no significant difference was observed. Similar results were obtained in a sub-analysis stratified by baseline vision. Around half the patients in our study had baseline vision $\geq 70$ approxETDRS letters, which remained stable regardless of DM treatment type (Table 2). Previous studies have shown improved final vision in patients with good baseline vision, although improvements are typically less than in those with poor baseline vision [28]. Conversely, there have also been reports of poor final vision in patients with poor starting vision $[28,29]$. In our study, for both categories of baseline vision, the two treatment groups had comparable final BCVA and CMT, indicating similar effectiveness of anti-VEGF therapy, regardless of diabetes treatment modality or baseline vision. Moreover, no significant difference was seen between the two treatment groups even in the sub-cohort with a good visual outcome at the end of 12 months, (Final BCVA $\geq 70$ approxETDRS). Several potential confounders were present in this study; the insulin group had a significantly longer duration of DM as well as higher proportions of severe retinopathy and higher proportions of PRP laser at baseline. Likewise, the proportions of nephropathy, HTN as well as phakic participants, were significantly higher in the insulin group. However, vision and CMT at 12 months had improved significantly in this group, indicating no adverse effects of insulin on treatment outcome. Further, a multivariable regression analysis adjusting for the baseline parameters showed no difference in the final outcome between the two treatment groups (Additional File: Supplementary S1). The previously reported association of insulin with the progression of DR/DME might be due to pre-existing poor diabetes control before the initiation of insulin therapy, possibly owing to the hyperglycemic memory phenomenon [30]. In addition, previous frontline treatment for DME (grid/focal laser) [31] was less effective than current anti-VEGF treatments and DME typically progressed in most patients [32]. Our study shows that insulin treatment per se does not influence anti-VEGF treatment outcomes.

A study by Matsuda et al. [25] analyzed 96 T2DM (49 insulin, 46 OHA) patients receiving anti-VEGF injections for DME. They also found no significant difference in visual outcomes between the two treatment groups at the end of 12 months, though both groups had significant improvement in vision. Another recent study by Logeswaran et al. [26] looked at the possible influence of insulin therapy on macular thickness reduction in patients receiving intravitreal anti-VEGF injections. Again, this study failed to identify any significant difference between the insulin and the non-insulin group. However, the study had a very short follow-up duration of only one month and the two patient groups were evaluated only on macular thickness criteria. The current study extended this duration to one more relevant to extended patient treatment regimens and also assessed 
visual outcome, which is arguably more important to patient function than macular thickness. These realworld findings corroborate those from a randomized clinical trial [33]. A two-year post hoc analysis of the RIDE and RISE trials, exploring the effect of systemic risk factors for DME, showed a similar visual response to the anti-VEGF agent, ranibizumab, between insulin and non-insulin patient groups. The post hoc analysis further classified the treatment group into three sub-groups comprising insulin only, insulin plus other OHAs, and other OHAs.

This study has some limitations that are inherent to a retrospective observational design and a relatively small cohort size. A true effect of insulin on the treatment of DME in T2DM would require comparison between T2DM patients "only on OHA" vs patients "only on insulin (without prior use of OHA)". However, for the majority of T2DM patients, including those in our study, the initial drug of choice for the management of hyperglycemia is OHA, followed by insulin in the event they fail to respond to OHA or if any side effects occur [34]. Consequently, most, if not all, T2DM patients would commence on $\mathrm{OHA}$, and hence a true treatment naïve cohort for insulin (without prior use of OHA) would not be feasible. Information regarding the time point of insulin therapy initiation and duration of insulin therapy would have been beneficial. This would have allowed exploration of the effect of acute vs chronic insulin therapy on anti-VEGF response. However, considering the fact that both the insulin and OHA group had a mean DM duration of more than 8 years, most of our cases are likely to be chronic insulin users and our study would have missed the early worsening phase of DR/DME post-initiation of insulin treatment. Further, data on the formulations and methods of insulin administration were not available owing to the retrospective design. For similar reasons, detailed data regarding the type of OHAs used were also not available for all the participants, and hence a more indepth analysis could not be done. Thiazolidinediones (a type of OHA) have been suggested to be associated with DME in a few case reports [35, 36], whereas other OHAs such as dipeptidyl peptidase-4 (DPP4) inhibitors [37] and sodium-glucose cotransporter 2 inhibitors (SGLT2i) [38] have been reported to be protective against DR. However, a large, cross-sectional ACCORD Eye Study [39] demonstrated no association between thiazolidinediones and DME in T2 diabetics and similarly, a recent study by Kang et al. [40] on the add-on effect of DPP4 on DR in T2 diabetics showed inconclusive evidence. Nevertheless, a larger prospective study on T2DM patients receiving anti-VEGF injections, with details on the different insulin formulations, duration of insulin therapy, and various types of OHAs, would provide a better understanding of the possible adverse effects of different treatment modalities on DME outcomes. As outlined in the methodology section, the Snellen's visual acuity in this study was converted to approxETDRS. Such conversion, however, cannot be assumed to be equivalent to "true" ETDRS letter scores obtained using a standard ETDRS chart, and hence should be interpreted with caution, especially when dealing with few letters difference [27]. Further, we evaluated the effect of glycemic control at baseline but were unable to assess it at final follow-up due to insufficient data. Finally, a combination of different anti-VEGF agents was used over the one-year period for the majority of our participants, reflecting real-world practice. Analysis by injection sub-type showed similar outcomes in the two groups (Additional File: Supplementary S2).

\section{Conclusion}

In summary, our study showed that insulin therapy does not alter visual outcomes for T2 diabetics receiving antiVEGF injections and patients do not need to alter their diabetes medication to optimize their eye care. Of key clinical relevance, we found no association between insulin treatment and sub-optimal vision or CMT outcome. In fact, these patients showed significant improvements in both of these outcomes. As insulin improves glycemic control, it may even be positively associated with a better anti-VEGF response in the long term. A prospective study with longer follow-up would help to explore this further.

\section{Supplementary Information}

The online version contains supplementary material available at https://doi. org/10.1186/s12886-022-02325-x.

Additional file 1.

\section{Acknowledgements}

The authors would like to acknowledge all the clinical staff and patients of Royal Hobart Hospital Department of Ophthalmology, Hobart Eye Surgeons, Launceston Eye Institute, and Flinders Medical Center Eye Clinic (Adelaide) for their support during patient recruitment and data collection.

\section{Authors' contributions}

RLG, KPB, LMF, BJM, NV conceived the concept for this study. RLG performed the statistical analysis and wrote the initial draft of the manuscript. LMF, BJM, $\mathrm{AWH}, \mathrm{NV}, \mathrm{KPB}, \mathrm{EL}, \mathrm{GK}, \mathrm{BR}, \mathrm{BJ}$, JC were involved in critical revision of the manuscript. The author(s) read and approved the final manuscript.

\section{Funding}

The study was funded by the Tasmanian Community Fund and the National Health and Medical Research Council (NHMRC) Australia Centre for Research Excellence (GNT1116360). RLG is supported by a scholarship from Diabetes Tasmania and the Patricia F Gordon Postgraduate Top-Up Scholarship in Medical Research. LMF is supported by a Cancer Council Tasmania/College of Health and Medicine, University of Tasmania Fellowship. KPB is supported by NHMRC Senior Research Fellowship.

Availability of data and materials

Data are available upon reasonable request. 


\section{Declarations}

\section{Competing interests}

The authors declare no competing interests.

\section{Ethics approval and consent to participate}

This study adhered to the tenets of the Declaration of Helsinki and was approved through the Human Research Ethics Committee, University of Tasmania (approval number H0012902), and the Southern Adelaide Clinical Human Research Ethics Committee (approval number 86-067). Written informed consent was sought from all the participants.

\section{Consent for publication}

Not applicable.

\section{Conflicts of interest}

None.

\section{Author details}

'Menzies Institute for Medical Research, University of Tasmania, 17 Liverpool Street (Private Bag 23), Hobart, Tas 7000, Australia. ${ }^{2}$ Department of Ophthalmology, Flinders Health and Medical Research Institute, Flinders University, Adelaide, South, Australia. ${ }^{3}$ School of Medicine, University of Tasmania, Hobart, TAS, Australia.

Received: 6 November 2021 Accepted: 17 February 2022

Published online: 28 February 2022

\section{References}

1. Klein R, Knudtson MD, Lee KE, Gangnon R, Klein BE. The Wisconsin epidemiologic study of diabetic retinopathy XXIII: the twenty-five-year incidence of macular edema in persons with type 1 diabetes. Ophthalmology. 2009:116(3):497-503.

2. Raman R, Rani PK, Rachepalle SR, Gnanamoorthy P, Uthra S, Kumaramanickavel G, et al. Prevalence of diabetic retinopathy in India: Sankara Nethralaya diabetic retinopathy epidemiology and molecular genetics study report 2. Ophthalmology. 2009;116(2):311-8.

3. Yau JW, Rogers SL, Kawasaki R, Lamoureux EL, Kowalski JW, BekT, et al. Global prevalence and major risk factors of diabetic retinopathy. Diabetes Care. 2012;35(3):556-64

4. Varma R, Bressler NM, Doan QV, Gleeson M, Danese M, Bower JK, et al. Prevalence of and risk factors for diabetic macular edema in the United States. JAMA ophthalmol. 2014;132(11):1334-40.

5. Diep TM, Tsui I. Risk factors associated with diabetic macular edema. Diabetes Res Clin Pract. 2013;100(3):298-305

6. Zhang X, Zhao J, Zhao T, Liu H. Effects of intensive glycemic control in ocular complications in patients with type 2 diabetes: a meta-analysis of randomized clinical trials. Endocrine. 2015:49(1):78-89.

7. Rotella CM, Pala L, Mannucci E. Role of insulin in the type 2 diabetes therapy: past, present and future. Int J Endocrinol Metab. 2013;11(3):137.

8. Home P, Riddle M, Cefalu WT, Bailey CJ, Bretzel RG, Del Prato S, et al. Insulin therapy in people with type 2 diabetes: opportunities and challenges? Diabetes Care. 2014:37(6):1499-508.

9. Bowker SL, Majumdar SR, Veugelers P, Johnson JA. Increased cancerrelated mortality for patients with type 2 diabetes who use sulfonylureas or insulin. Diabetes Care. 2006;29(2):254-8.

10. Herman ME, O'Keefe JH, Bell DS, Schwartz SS. Insulin therapy increases cardiovascular risk in type 2 diabetes. Prog Cardiovasc Dis. 2017:60(3):422-34.

11. Zhang J, Ma J, Zhou N, Zhang B, An J. Insulin use and risk of diabetic macular edema in diabetes mellitus: a systemic review and meta-analysis of observational studies. Med Sci Monit. 2015;21:929.

12. Lauritzen T, Frost-Larsen K, Larsen H-W, Deckert T, Group SS. Two-year experience with continuous subcutaneous insulin infusion in relation to retinopathy and neuropathy. Diabetes. 1985;34(Supplement 3):74-9.

13. Henricsson M, Berntorp K, Fernlund P, Sundkvist G. Progression of retinopathy in insulin-treated type 2 diabetic patients. Diabetes Care. 2002:25(2):381-5.
14. Henricsson M, Janzon L, Groop L. Progression of retinopathy after change of treatment from oral antihyperglycemic agents to insulin in patients with NIDDM. Diabetes Care. 1995:18(12):1571-6.

15. Zapata MA, Badal J, Fonollosa A, Boixadera A, García-Arumí J. Insulin resistance and diabetic macular oedema in type 2 diabetes mellitus. $\mathrm{Br} J$ Ophthalmol. 2010;94(9):1230-2

16. Cleary PA, Dahms W, Goldstein D, Malone J, Tamborlane WV. Beneficial effects of intensive therapy of diabetes during adolescence: outcomes after the conclusion of the Diabetes Control and Complications Trial (DCCT). J Pediatr. 2001;139:804-12.

17. Henricsson M, Nilsson A, Janzon L, Groop L. The effect of glycaemic control and the introduction of insulin therapy on retinopathy in non-insulindependent diabetes mellitus. Diabet Med. 1997;14(2):123-31.

18. Martin A, Komada MR, Sane DC. Abnormal angiogenesis in diabetes mellitus. Med Res Rev. 2003;23(2):117-45.

19. Zhao C, Wang W, Xu D, Li H, Li M, Wang F. Insulin and risk of diabetic retinopathy in patients with type 2 diabetes mellitus: data from a metaanalysis of seven cohort studies. Diagn Pathol. 2014:9(1):1-7.

20. Lassance L, Miedl H, Absenger M, Diaz-Perez F, Lang U, Desoye G, et al. Hyperinsulinemia stimulates angiogenesis of human fetoplacental endothelial cells: a possible role of insulin in placental hypervascularization in diabetes mellitus. J Clin Endocrinol Metab. 2013:98(9):E1438-47.

21. Escudero CA, Herlitz K, Troncoso F, Guevara K, Acurio J, Aguayo C, et al. Pro-angiogenic role of insulin: from physiology to pathology. Front Physiol. 2017:8:204

22. Liu Y, Petreaca M, Martins-Green M. Cell and molecular mechanisms of insulin-induced angiogenesis. J Cell Mol Med. 2009:13(11-12):4492-504.

23. Wright WS, McElhatten RM, Messina JE, Harris NR. Hypoxia and the expression of HIF-1 $a$ and HIF-2a in the retina of streptozotocin-injected mice and rats. Exp Eye Res. 2010;90(3):405-12.

24. Sugimoto M, Cutler A, Shen B, Moss SE, Iyengar SK, Klein R, et al. Inhibition of EGF signaling protects the diabetic retina from insulin-induced vascular leakage. Am J Pathol. 2013;183(3):987-95.

25. Matsuda S, Tam T, Singh RP, Kaiser PK, Petkovsek D, Zanella MT, et al. Impact of insulin treatment in diabetic macular edema therapy in type 2 diabetes. Can J Diabetes. 2015:39(1):73-7.

26. Logeswaran A, Jindachomthong KK, Ness S, Siegel NH, Subramanian ML, Chen X. Effect of Insulin-based Medications on the effectiveness of antivascular endothelial growth factor injections in diabetic macular edema. Invest Ophthalmol Vis Sci. 2020:61(7):3295.

27. Gregori NZ, Feuer W, Rosenfeld PJ. Novel method for analyzing snellen visual acuity measurements. Retina. 2010;30(7):1046-50.

28. Sophie R, Lu N, Campochiaro PA. Predictors of functional and anatomic outcomes in patients with diabetic macular edema treated with ranibizumab. Ophthalmology. 2015;122(7):1395-401

29. Channa R, Sophie R, Khwaja A, Do D, Hafiz G, Nguyen Q, et al. Factors affecting visual outcomes in patients with diabetic macular edema treated with ranibizumab. Eye (Lond). 2014;28(3):269.

30. Testa R, Bonfigli AR, Prattichizzo F, La Sala L, De Nigris V, Ceriello A. The, "metabolic memory" theory and the early treatment of hyperglycemia in prevention of diabetic complications. Nutrients. 2017:9(5):437.

31. Photocoagulation for diabetic macular edema. Early Treatment Diabetic Retinopathy Study report number 1. Early Treatment Diabetic Retinopathy Study research group. Arch Ophthalmol. 1985;103(12):1796-806.

32. Elman MJ, Aiello LP, Beck RW, Bressler NM, Bressler SB, Edwards AR, et al. Randomized trial evaluating ranibizumab plus prompt or deferred laser or triamcinolone plus prompt laser for diabetic macular edema. Ophthalmology. 2010;117(6):1064-77 (e35).

33. Singh RP, Habbu K, Ehlers JP, Lansang MC, Hill L, Stoilov I. The impact of systemic factors on clinical response to ranibizumab for diabetic macular edema. Ophthalmology. 2016;123(7):1581-7

34. Wong J, Tabet E. The introduction of insulin in type 2 diabetes mellitus. Aust Fam Physician. 2015;44(5):278-83.

35. Colucciello M. Vision loss due to macular edema induced by rosiglitazone treatment of diabetes mellitus. Arch Ophthalmol. 2005;123(9):1273-5.

36. Ryan EH Jr, Han DP, Ramsay RC, Cantrill HL, Bennett SR, Dev S, et al. Diabetic macular edema associated with glitazone use. Retina. 2006;26(5):562-70.

37. Chung Y-R, Park SW, Kim JW, Kim JH, Lee K. Protective effects of dipeptidy peptidase-4 inhibitors on progression of diabetic retinopathy in patients with type 2 diabetes. Retina. 2016:36(12):2357-63. 
38 Cho EH, Park S-J, Han S, Song JH, Lee K, Chung Y-R. Potent oral hypoglycemic agents for microvascular complication: sodium-glucose cotransporter 2 inhibitors for diabetic retinopathy. J Diabetes Res. 2018;2018:6807219.

39. Ambrosius WT, Danis RP, Goff DC, Greven CM, Gerstein HC, Cohen RM, et al. Lack of association between thiazolidinediones and macular edema in type 2 diabetes: the ACCORD eye substudy. Arch Ophthalmol. 2010;128(3):312-8.

40 Kang EY-C, Kang C, Wu W-C, Sun C-C, Chen KJ, Lai C-C, et al. Association between add-on dipeptidyl peptidase-4 inhibitor therapy and diabetic retinopathy progression. J Clin Med. 2021;10(13):2871.

\section{Publisher's Note}

Springer Nature remains neutral with regard to jurisdictional claims in published maps and institutional affiliations.

- fast, convenient online submission

- thorough peer review by experienced researchers in your field

- rapid publication on acceptance

- support for research data, including large and complex data types

- gold Open Access which fosters wider collaboration and increased citations

- maximum visibility for your research: over 100M website views per year

At BMC, research is always in progress.

Learn more biomedcentral.com/submissions 